\title{
ORALIDADE E AUDITIVIDADE. TENTATIVA DE UM MAPEAMENTO TEÓRICO ${ }^{1}$ \\ Orality and auditivity: An attempt of theoretical mapping
}

\author{
Gabriel Borowski ${ }^{2}$
}

\begin{abstract}
RESUMO: O presente esboço consiste numa tentativa de revisão do conceito de auditividade, insinuado por Antonio Candido, elaborado por Luiz Costa Lima, desenvolvido por João Cezar de Castro Rocha e retomado atualmente por Marília Librandi-Rocha. O meu objetivo é apontar para a pertinência da relação de distância ou proximidade entre os sujeitos envolvidos numa modalidade específica de comunicação, isto é, a comunicação literária. No final do trabalho evoco um estudo de Marisa Lajolo para introduzir uma distinção entre a persuasão oral de caráter integrador, que visa a uma sensação de comunidade entre o narrador e o destinatário, e a persuasão auditiva de caráter desagregador, que reforça a distância entre o emissor e o receptor.

PALAVRAS-CHAVE: Oralidade; Auditividade; Comunicação; Narrador; Destinatário.
\end{abstract}

\begin{abstract}
This paper is an attempt to review the concept of auditivity, which has been introduced implicitly by Antonio Candido, elaborated by Luiz Costa Lima, developed by João Cezar de Castro Rocha and currently is being taken up by Marília Librandi-Rocha. My objective is to point out the relevance of the relationship of distance and proximity between subjects involved in a specific mode of communication, that is, literary communication. I also evoke a paper by Marisa Lajolo in order to introduce a distinction between the oral persuasion, which integrates and aims to create a sense of community between the narrator and the narratee, and the auditive persuasion, which disintegrates and reinforces the distance between the transmitter and the receiver.
\end{abstract}

KEYWORDS: Auditivity; Orality and Literacy; Persuasion; Literary Communication; Luiz Costa Lima.

${ }^{1}$ O presente trabalho resulta do apoio financeiro concedido pelo Ministério da Ciência e Ensino Superior da República da Polônia no âmbito do programa "Bolsa Diamantina" para a realização do projeto de pesquisa intitulado "A ficção autonarrativa no Brasil e a (sua) identidade" (DI2011 019841) nos anos 2012-2016. O presente artigo constitui uma versão ligeiramente alterada de uma parte do segundo capítulo de minha tese de doutorado intitulada $A$ autonarrativa ficcional no Brasil: identidade moderna e cultura auditiva (o caso Machado de Assis), apresentada na Faculdade de Filologia da Universidade Jaguelônica em outubro de 2015.

2 Doutor em Estudos Literários pela Faculdade de Filologia da Universidade Jaguelônica de Cracóvia (Polônia). 
Quando se trata da relação antagônica entre a oralidade e a modernidade convém evocar o famoso ensaio de Walter Benjamin sobre o narrador, em que as práticas narrativas como modo de "intercambiar experiências" num contexto coletivo são contrastadas com a impessoalidade do objeto impresso:

O primeiro indício da evolução que vai culminar na morte da narrativa é o surgimento do romance no início do período moderno. $\mathrm{O}$ que separa o romance da narrativa (e da epopeia no sentido estrito) é que ele está essencialmente vinculado ao livro. A difusão do romance só se torna possível com a invenção da imprensa. [...] O narrador retira da experiência o que ele conta: sua própria experiência ou a relatada pelos outros. E incorpora as coisas narradas à experiência dos seus ouvintes. O romancista segrega-se. A origem do romance é o indivíduo isolado, que não pode mais falar exemplarmente sobre suas preocupações mais importantes e que não recebe conselhos nem sabe dá-los. (BENJAMIN, [1936] 1994, p. 201).

Para Benjamin, a modernidade implica a segregação dos indivíduos, um afastamento das práticas coletivas típicas da narração oral. Já que o próprio ato de escrever costuma assumir forma de uma empresa solitária, a escrita, como processo, implica um distanciamento entre o narrador e o seu público, pelo menos na fase da produção. Desse modo, ela impede qualquer questionamento do discurso que transcenda os limites do próprio texto ( $c f$. OLSON, [1994] 1996, p. 65-114) - fato não alterado nem pelos comentários do autor, que constituem no máximo um metatexto, mas nunca o texto em si. $\mathrm{O}$ texto escrito não consegue também, devido às limitações do seu próprio sistema simbólico, comunicar plenamente as atitudes do narrador em relação ao narrado. À vista disso, cada ato de leitura pode (ou mesmo precisa) levar a uma interpretação diferente. Este fato, bastante óbvio do ponto de vista da teoria pós-moderna da literatura, possui implicações importantes em sociedades que, apesar da interiorização irreversível dos mecanismos da escrita, resgatam uma "oralidade secundária" (secondary orality) (ONG [1982] 2012, p. 3, 11, 133-134). O costume da leitura em voz alta, muito difundido no Brasil até, pelo menos, o final do século XIX (LAJOLO; ZILBERMAN, [1996] 1998, p. 266-271; CANDIDO, [1955] 2011, p. 94), é um bom exemplo disso: não dispondo de indicações intratextuais a respeito de todos os elementos que envolvem o corpo no 
processo da leitura em voz alta, o leitor desempenha, nesse sentido, um papel decisivo na produção do significado.

\section{UMA VOZ PERSUASIVA}

Sobrepondo-se à visão antagônica de Benjamin, a atenção dos pesquisadores no âmbito dos estudos sobre a oralidade - como sugere, entre outros, o esboço de Galvão e Batista (2006) e o calendário elaborado por Czapliński (2010, p. 354-371) - orienta-se cada vez mais, desde meados da década de 1970, para a relação entre a oralidade e a escrita e para a presença do resíduo oral nas culturas quirográficas e, posteriormente, também tipográficas. Em 1973, na revista New Literary History ${ }^{3}$ - no número dedicado ao problema "O que é a literatura?", que reúne algumas contribuições (de Todorov, Butler, Kernan, Fish, Roberts, Ricoeur, Seem e Adams) que orientarão as pesquisas no âmbito dos estudos literários nas décadas posteriores - Robert Kellogg publica o artigo Oral Literature, em que defende que:

The multitudinous ways in which literature can in some sense or another be said to incorporate the oral [...] suggests a wide spectrum of verbal media rather than a simple opposition between print and speech. (KELLOGG, 1973, p. 65).

Como afirma Kellogg: "We seem, [...], to know almost intuitively that literature was in the first place created by one person speaking to others and that this primal situation of oral performance is still being re-created or imitated by most literary works." (KELLOG, 1973, p. 55). No que concerne à presença do resíduo oral na literatura, costuma-se evocar autores que, familiarizados com as técnicas da escrita, e funcionando numa cultura de índole quirográfica ou tipográfica, imitam um discurso oral, chamando atenção à existência de uma voz narrativa que enuncia o texto. Os narradores que se expõem perante o leitor, exibindo sua singularidade, parecem exemplos mais adequados para esse tipo de literatura, lançando uma ponte entre a produção oral e escrita. Para Kellogg, no entanto, eles constituem apenas uma das opções possíveis - aliás, uma modalidade já muito influenciada pela escrita. Ao contrário da tradição dos bardos, que apagam a

\footnotetext{
${ }^{3}$ Vale a pena notar que em 1977 New Literary History dedica um número inteiro (v. 8, n. 3) ao tema "Oral Cultures and Oral Performances", o que evidencia a importância do problema - e das suas implicações para o campo da teoria literária - no final da década de 70. Em 1984 a mesma revista lança um número (v. 16, n. 1) subordinado ao tema "Oral and Written Traditions in the Middle Ages".
}

Miscelânea, Assis, v. 21, p. 31-50, jan.- jun. 2017. ISSN 1984-2899 
sua individualidade para criar condições propícias para a evocação do passado coletivo, o narrador autoconsciente chama a atenção do seu público para si mesmo. A distância entre o poeta e o seu público, que resulta numa crise da noção de coletividade baseada na dinâmica de participação, originase da introdução do conceito de autoria. Esta, por sua vez, pertence à ordem da escrita, uma vez que tanto a ideia do texto como um artefato, com uma forma fixa e estabelecida uma vez por todas, quanto a apreensão desse mesmo texto enquanto objeto que pode ser possuído por um indivíduo, são possíveis apenas numa cultura que interiorizou um conjunto de práticas que permitem a perpetuação do texto ( $c f$. HAVELOCK, 1984, p. 185-186).

Kellogg propõe, portanto, uma divisão entre uma literatura primeira e secundariamente épica. Aquela diz respeito à tradição dos bardos, declamadores que pertencem à coletividade, e, através do seu discurso, em que eliminam sua própria invenção e individualidade, procuram compor narrativas que evoquem histórias e figuras importantes para a situação atual do grupo. É uma voz da tradição oral participativa, focada na conservação do passado mítico. A outra modalidade abrange a cultura oratória, influenciada pela retórica clássica, em que o caráter do narrador é manipulado, visando conseguir um efeito persuasivo no seu auditório (KELLOG, 1973, p. 61). O pesquisador alega que, obedecendo aos preceitos da tradição retórica da antiguidade, o renascimento europeu favoreceu o discurso oficial como forma preferida de toda narrativa. $\mathrm{O}$ destaque à singularidade que caracteriza os narradores na épica secundária foi reforçado no romantismo, conjugando-se, paradoxalmente, com o substrato tradicional da cultura dos bardos. Desse modo, no século XVIII e XIX cristaliza-se uma voz narrativa altamente condicionada pelas regras da retórica e orientada para fins persuasivos, realçando, por isso, a distância entre o narrador e o público. Se, como afirma Kellogg (1973, p. 62), "[t]he oration, both actual and as model for literary works, constitutes a medium of discourse intermediate between a purely oral, bardic tradition and one in which through the medium of the written book an author can address a solitary reader", as formas oratórias na literatura permitem uma abordagem dupla, se situando na fronteira entre o discurso oral e o discurso escrito vinculado ao livro. ${ }^{4}$

\footnotetext{
${ }^{4}$ Importa observar que, embora se refira ao discurso oral, a retórica como arte ou ciência, ordenada e analítica, é um produto da cultura da escrita. A elaboração de um conjunto de regras e preceitos (como o exemplo paradigmático, a Retórica, de Aristóteles) deve ter se baseado primeiro numa análise de vários discursos perpetuados através da escrita, já que, como alega Ong ([1982] 2011, p. 39, 170-174), a escrita não reduz a oralidade, mas antes a realça, permitindo um estudo dos recursos e efeitos da fala. Este estudo, porém, não visava um conhecimento linguístico, orientado para o conhecimento em si, mas antes mantinha relações muito estreitas com a política, desenvolvendo capacidades necessárias para objetivos práticos, isto é, fins persuasivos (ONG, [1988] 2009, p. 261).
}

Miscelânea, Assis, v. 21, p. 31-50, jan.- jun. 2017. ISSN 1984-2899 
A orientação persuasiva da retórica clássica, porém, não contradizia o caráter participativo da antiga cultura oral, procurando incentivar os membros da coletividade à ação (ONG, 1976, p. 18). O fim da cultura retórica propriamente dita, e do seu papel de intermediário entre a cultura oral e a cultura da escrita, dá-se, segundo Ong ([1971] 2009), com a profunda interiorização da tecnologia da impressão na época do romantismo. O período coincide, portanto, com a formação de uma nova voz narrativa (a "épica secundária" de Kellogg), que se serve dos recursos retóricos e mecanismos da oralidade com fins persuasivos, mas que já não procura a participação e a proximidade do auditório, sublinhando sua singularidade.

\section{CANDIDO: TRADIÇÃO DE AUDITÓRIO}

Como se vê, uma série de transformações dos meios de comunicação, que marcou o processo de interiorização da escrita na cultura europeia ao longo dos séculos, leva à constituição de uma nova voz narrativa. Esta, conjugando o seu suporte material (o livro impresso) com os recursos da retórica clássica (baseada na escrita, mas destinada para o discurso oral), orienta-se para um efeito persuasivo, procurando manipular o leitor para conseguir fins específicos. Essa voz, já distanciada do padrão participativo das culturas orais, fundamenta-se no afastamento entre o emissor e o público. Dado que ela se cristalizou no final do século XVIII e no início do século XIX, o auge da sua vigência literária coincidiu com os primórdios da literatura brasileira ( $c f$. CANDIDO, [1959] 2014), levando à formação de um narrador persuasivo, herdeiro do modelo oratório herdado das literaturas europeias, ainda que as acomode às condições socioculturais específicas.

Antonio Candido ([1955] 2011, p. 83-98) corrobora esta hipótese quando discute as condições socioculturais específicas da circulação da literatura no Brasil. ${ }^{5}$ Conforme o pesquisador, desde o período colonial, com a ação catequizadora dos pregadores, passando pela cultura dos conferencistas de academia, dos oradores e recitadores, e se estendendo até o hábito de leitura em voz alta nos serões no final do século XIX, a literatura brasileira sempre dependeu de um público de auditores. Candido sublinha a ligação da literatura no período imediatamente antes e depois da independência do país com as ideias políticas, o que proporcionou o primeiro contato do escritor - que devido à falta da divisão do trabalho intelectual no Brasil oitocentista não possuía um papel social definido - com o seu público

\footnotetext{
${ }^{5}$ As observações a respeito do estudo de Candido, Costa Lima e Chaui, apresentadas de uma forma muito resumida em BOROWSKI (2014), aparecem neste lugar numa versão ampliada e modificada.
}

Miscelânea, Assis, v. 21, p. 31-50, jan.- jun. 2017. ISSN 1984-2899 
potencial. O romantismo, como o primeiro movimento literário do Brasil independente, apresentava uma fusão de retórica e nativismo, servindo-se dos meios de comunicação disponíveis: "Se as edições dos livros eram parcas, e lentamente esgotadas, a revista, o jornal, a tribuna, o recitativo, a cópia volante, conduziam as suas ideias ao público de homens livres, dispostos a vibras na grande emoção do tempo" (CANDIDO, [1955] 2011, p. 90). A "tradição de auditório (ou que melhor nome tenha)" (CANDIDO, [1955] 2011, p. 94) permitiu a penetração da produção romântica e pós-romântica na sociedade.

$\mathrm{Na}$ ótica de Candido, os primeiros momentos da literatura brasileira - e, na verdade, todo o século XIX, até o advento do movimento modernista - possibilitavam um encontro próximo do autor com o seu público, permitindo a criação de uma comunidade. Esta, no entanto, compreendia apenas os representantes de pequenas elites ("Elite literária, no Brasil, significou até bem pouco tempo, não refinamento de gosto, mas apenas capacidade de interessar-se pelas letras"; CANDIDO, [1955] 2011, p. 95), excluindo outros grupos sociais. Essas circunstâncias levaram à ausência de diálogo efetivo entre o escritor e o seu público. O escritor não dispunha de um público suficientemente vasto para poder dispensar do apoio das pequenas classes privilegiadas. Constituiu-se, portanto, um campo literário muito peculiar, marcado pela proximidade do escritor em relação às elites, e pelo seu distanciamento do público mais vasto.

Essa situação promoveu a formação de um estilo fácil e acessível com fortes marcas da oralidade:

Deste modo, formou-se, dispensando o intermédio da página impressa, um público de auditores, muito maior do que se dependesse dela e favorecendo, ou mesmo requerendo, no escritor, certas características de facilidade e ênfase, certo ritmo oratório que passou a timbre de boa literatura e prejudicou entre nós [os brasileiros] a formação dum estilo realmente escrito para ser lido. A grande maioria dos nossos escritores, em prosa e verso, fala de pena em punho e prefigura um leitor que ouve o som da sua voz brotar a cada passo por entre as linhas. (CANDIDO, [1955] 2011, p. 91, grifos no original).

No final do mesmo ensaio, o pesquisador sublinha a persistência dessa "tradição de auditório" que favorece um tipo de literatura "que tem muitas características de produção falada para ser ouvida" (CANDIDO, [1955] 2011, p. 98). Evocando Machado de Assis como exemplo de "um possível enriquecimento da leitura e da escrita feita para ser lida"

Miscelânea, Assis, v. 21, p. 31-50, jan.- jun. 2017. ISSN 1984-2899 
(CANDIDO, [1955] 2011, p. 98), Candido mostra também as tendências contrárias, originadas pela transformação dos meios de comunicação de massa em meados do século passado, como o rádio, que resgata a literatura oral. Também as transformações sociais, como a ascensão da classe trabalhadora, constituiu, segundo o pesquisador, um reforço para a oratória, favorecida pelos "romancistas, poetas e ensaístas, que não raro escrevem como quem fala para convencer ou comover" (CANDIDO, [1955] 2011, p. 98).

\section{LIMA: ESTILO AUDITIVO}

A reflexão de Antonio Candido será retomada no final da década de 1970 por Luiz Costa Lima. No seu ensaio intitulado Da existência precária: o sistema intelectual no Brasil, publicado originalmente em 1978 (LIMA, [1978] 1981, p. 3-29), o pesquisador apresenta um esboço do processo da formação do sistema intelectual no país, apontando para "marcas que constituem o nosso [brasileiro] legado cultural" (LIMA, [1978] 1981, p. $5)$.

A condição colonial, culturalmente dependente do Brasil, que se traduzia pela inexistência de um público leitor propriamente dito - fato já sublinhado por Candido nos trabalhos supracitados - inviabilizam a constituição de um diálogo efetivo entre o leitor e o escritor que pudesse resultar no desenvolvimento criativo dos padrões europeus herdados. Conforme Costa Lima, a independência política do Brasil não introduziu alterações substanciais ao quadro, de modo que o século XIX continuou a ser impregnado por um padrão comunicativo que prejudicava a formação de formas de expressão mais elaboradas e mais exigentes do ponto de vista interpretativo. Desse modo,

embora o romantismo já tivesse tipografias à sua disposição, a literatura continuava fundamentalmente cúmplice da oralidade. E a maneira de converter a página escrita em forma oral consistia em oferecer uma leitura fácil, fluente, embalada pela ritmicidade dos versos iguais [...] e pela prosa digestiva, de tema nativista e/ou sentimental. (LIMA, [1978] 1981, p. 7).

Assim sendo, "a forma escrita da literatura fazia-se a sucursal de uma circulação permanentemente oral” (LIMA, [1978] 1981, p. 7). Em consequência dessa concentração quase exclusiva nos aspectos formais, puramente retóricos do discurso, conjugada com papel moralista que, devido a pouca divisão do trabalho intelectual (cf. CANDIDO, [1953/1955] 2011, p.

Miscelânea, Assis, v. 21, p. 31-50, jan.- jun. 2017. ISSN 1984-2899 
139 e passim), se atribuía ao intelectual, este "foi [...] aceito não enquanto agente de ideias e de aprofundamento da linguagem, mas apenas enquanto especialista no verbo fácil, na palavra comovente e, daí, enquanto orientador de caminhos" (LIMA, [1978] 1981, p. 8).

Para denominar esta modalidade de comunicação, o estudioso introduz o conceito de auditividade, que se distingue tanto da oralidade quanto do padrão baseado na escrita. $\mathrm{O}$ pesquisador sublinha a diferença entre a cultura oral, que possui uma dinâmica de circulação do pensamento muito própria (neste ponto refere-se a um trabalho então muito recente de Ong, publicado em 1977), e a cultura auditiva como uma forma peculiar do sistema intelectual brasileiro. A auditividade consiste basicamente na predominância dos mecanismos da oralidade no interior de uma cultura da escrita, e, em consequência, tem um caráter prejudicial na formação e no amadurecimento de instituições dependentes dos processos escriturais. Nesse tipo de cultura, "a palavra é escolhida e a frase composta de maneira a suscitar um efeito que se quer o mais imediato possível" (LIMA, [1978] 1981 , p. 16), ou seja, o discurso visa a um impacto que prescinda do entendimento da parte do leitor, servindo-se de vários recursos que lhe permitam exercer uma influência instantânea.

Segundo Costa Lima, o caráter auditivo da cultura brasileira foi introduzido, sobretudo pelo ensino jesuítico que "consistia em impressionar o auditório, em esmagar a sua capacidade dialogal, em deixá-lo pasmo e boquiaberto ante a perícia verbal e a teatralização gesticulatória, maneiras de rapidamente subjugar o auditório" (LIMA, [1978] 1981, p. 16). A cultura auditiva, que "é profundamente um cultura de persuasão sem o entendimento", da "persuasão sedutora" (LIMA, [1978] 1981, p. 16), diferencia-se das culturas orais. A divergência principal consta no efeito pretendido pelo emissor dentro da comunidade: enquanto a persuasão oral procura a integração dos participantes, o discurso auditivo visa à submissão esta, porém, não pretende intimidar o auditório, mas concretiza-se de uma forma menos perceptível, por meio de sedução:

em sua versão romântica e moderna, o estilo auditivo é sedutor, não por horrorizar, por inspirar gestos de pesado arrependimento, que levavam a ser imediatamente engrossadas as filas dos confessionários, mas por seu tom acariciante, de conversa à beira da rede ou ao pé do fogo, de conversa despreocupada. (LIMA, [1978] 1981, p. 16-17).

Como se vê, segundo o pesquisador, o poder da auditividade não se restringe ao período colonial, mas se estende até a modernidade. 
Uma vez que, como se disse, na cultura auditiva não se procura um diálogo efetivo com o auditório, mas antes se visa a um efeito imediato, uma das suas características é uma obliteração das práticas demonstrativas. Evitase a revelação dos elos entre os elementos do argumento, apresentando ao público apenas o seu resultado final. Esse aspecto da auditividade a relaciona, na reflexão de Costa Lima, com o autoritarismo ${ }^{6}$, favorecido também pela dimensão desintegradora da persuasão auditiva, mas também com o seu caráter ostensivo, voltado para fora, porque nele "o que decisivamente importa não é o arranjo interno, a combinação exaustiva das peças do mobiliário mental, a fundação do capital simbólico, mas a apresentação externa, as insígnias e os brasões da cultura" (LIMA, [1978] 1981, p. 22).

\section{ROCHA:AUDITIVIDADE E CORDIALIDADE}

Desde a sua formulação no final da década de setenta, o conceito de auditividade - que, como se pretende mostrar, parece muito útil no âmbito dos estudos sobre a cultura brasileira - evoluiu muito pouco. Costa Lima se refere à questão novamente no ensaio Dependência cultural e estudos literários, incluído no volume Pensando nos trópicos: dispersa demanda II, publicado em 1991. O crítico procura nesse texto ir além das tradicionais explicações econômicas do caráter dependente dos intelectuais brasileiros em relação aos centros metropolitanos estrangeiros, e aponta para dois fatores culturais que

não operam de fora para dentro - i.e., não são explicados apenas pelo descaso ou falta de interesse dos administradores, políticos e burocratas - senão que de dentro para fora, i.e., por decorrência dos próprios valores com que julgamos a atividade intelectual. (LIMA, 1991, p. 270).

Ao lado do "culto da improvisação" (equivalente ao "mito do talento espontâneo"), o primeiro fator é precisamente a auditividade, cuja brevíssima abordagem "se apresenta como complemento" do ensaio de 1978.

\footnotetext{
${ }^{6}$ No ensaio Brasil: mito fundador e sociedade autoritária de Marilena Chaui ([2000] 2001), a autora reconhece que na sociedade brasileira, fortemente verticalizada, "as divisões sociais são naturalizadas em desigualdades postas como inferioridade natural" através "de um conjunto de práticas que ocultam a determinação histórica ou material da exploração, da discriminação e da dominação, e que, imaginariamente, estruturam a sociedade sob o signo da nação una e indivisa" (CHAUI, [2000] 2001, p. 89-90). Sobre a relação entre as ideias de Candido, Costa Lima e Chaui veja Borowski (2014).
}

Miscelânea, Assis, v. 21, p. 31-50, jan.- jun. 2017. ISSN 1984-2899 
Evocando, ainda que por alto, os trabalhos de Havelock e Zumthor sobre o modo de armazenagem e produção do conhecimento nas culturas orais, Costa Lima retoma as raízes coloniais da auditividade brasileira, baseada na manutenção dos hábitos de ensino medievais, transferidos pelas nações ibéricas - ligadas à Contrarreforma - para as terras americanas:

Vivia-se em um tempo que, aproximando-se ou já estando em vigência o domínio do espírito científico, nas colônias ibéricas continuava a vigorar um ensino baseado no culto da memória e da palavra persuasiva; de uma persuasividade que não visava à conquista de uma verdade nova, aberta pois à experiência, senão que à preservação da verdade já afirmada. O educando assim não só se mantinha afastado do ethos exigido pela escrita como muito menos atingia aquele exigido por uma cultura fundada na oralidade. Ficava na metade do caminho, “combinando" uma e outra. (LIMA, 1991, p. 271).

Em sintonia com o alegado caráter híbrido da cultura que se situa "no meio do caminho" entre o oral e o escrito, um importante aspecto da auditividade, insinuado como uma questão a ser explorada, é a sua alegada relação com o padrão de vida social brasileira defendido por Sérgio Buarque de Holanda em Raízes do Brasil:

mesmo porque a auditividade não se subordina nem ao ethos da oralidade, nem ao da escrita, ela permeia uma sociedade em que as relações privadas dão o tom e dominam mesmo na esfera pública [...]. Em vez de cogitarmos de uma relação apenas "espacial", como o seria se o auditivo e o desconforto com a obediência apenas correspondessem a características de uma mesma sociedade, ela há de ser vista em sua mútua dependência: a manutenção da auditividade implica conservarse uma relação "privada", mágica com a palavra escrita, confundir-se seu uso com seu efeito; substituir-se a obediência ao encadeamento demonstrativo por seu efeito no ouvido. (LIMA, 1991, p. 272).

Tal linha de estudo, apenas sinalizada por Costa Lima, é desenvolvida em 1998 no ensaio Literatura e cordialidade: o público e o privado na literatura brasileira, de João Cezar de Castro Rocha. O trabalho se fundamenta em uma leitura de Raizes do Brasil que não o restringe a uma suposta interpretação psicológica do povo brasileiro, mas antes considera a 
obra de Sérgio Buarque de Holanda uma análise de constantes sociais que orientam a vida coletiva no Brasil (ROCHA, 1998, p. 167).

Importa lembrar sucintamente o conceito da cordialidade que serve do ponto de partida para o ensaio de Rocha. No quinto capítulo de Raízes do Brasil, Holanda ([1936] 1995) esboça a figura do brasileiro como "homem cordial" (termo emprestado do escritor Ribeiro Couto), caracterizado por um conjunto de traços que concernem basicamente ao apagamento das fronteiras entre o espaço público e o espaço privado: "as relações que se criam na vida doméstica sempre forneceram o modelo obrigatório de qualquer composição social entre nós [brasileiros]" (HOLANDA, [1936] 1995, p. 146). Essa atitude, manifesta na falta de ritualismo, no emprego dos diminutivos, na omissão do nome de família no tratamento social, na intimidade com os santos, entre outros, recobre e diminui uma angústia da solidão: "No «homem cordial», a vida em sociedade é, de certo modo, uma verdadeira libertação do pavor que ele sente em viver consigo mesmo, em apoiar-se sobre si próprio em todas as circunstâncias da existência" (HOLANDA, [1936] 1995, p. 147).

Rocha explora a ideia de "horror às distâncias que parece constituir, [...], o traço mais específico do espírito brasileiro" (HOLANDA, [1936] 1995, p. 49) para mostrar as suas implicações na escrita literária. Para o pesquisador, a cordialidade é inextrincavelmente ligada com a oralidade: "O elemento que [...] define [o homem cordial] é menos a escrita do que a fala e, sobretudo, a proximidade espacial que ela supõe. Por isso, todo texto parece evidenciar o desejo pelo corpo excluído com o advento dos tipos impressos" (ROCHA, 1998, p. 174). Desse modo, a cordialidade coloca-se na contracorrente em relação aos mecanismos alienadores que operam na comunicação dentro da cultura tipográfica moderna.

A noção de "uma leitura ao pé-do-ouvido" como modo de recepção da literatura típico para o contexto auditivo, proposta por Rocha, corrobora-se pelos hábitos da leitura em voz alta no século XIX, quando "a consulta individual ao texto se transformava facilmente na leitura coletiva do grupo familiar ou da roda de amigos em torno de um narrador" (ROCHA, 1998: 176). Desse modo, "abstração que a palavra impressa supõe era, [...], mitigada no convívio aurático de corpos aproximados pela formação de um círculo de leitura" (ROCHA, 1998, p. 176). Por isso, o pesquisador alega que os estudos sobre a difusão da cultura impressa na América Latina oitocentista deviam compará-la com a situação na Europa nos séculos imediatamente posteriores à invenção de Gutenberg, sendo possível, num movimento inverso, utilizar o conceito de auditividade também para o estudo da ficção europeia até o início do século XVIII (ROCHA, 1998, p. 179). A ampliação do emprego do termo, de modo que abranja "todas as situações de introdução da palavra impressa num circuito comunicativo anteriormente dominado pela transmissão oral" (ROCHA, 1998, p. 188), transforma a auditividade numa 
marca de transição de uma cultura em que a escrita ocupa uma posição periférica para um modelo de sociedade letrada.

Embora a auditividade enquanto um padrão meramente comunicativo - equivalente a uma prevalência das práticas orais numa cultura da escrita - não constitua, para Rocha, uma característica particularmente brasileira, o conceito mantém elementos marcantes, dado que "em relação ao campo discursivo do Brasil oitocentista, o que realmente o singulariza é o predomínio do campo semântico referente à fala e à audição num dia-a-dia marcado pela predominância da esfera privada" (ROCHA, 1998, p. 188). Outro elemento é o recurso à autoridade que substitui uma discussão impessoal sobre os conceitos por uma intimidade ilusória com os grandes mestres evocados. As consequências desse estado são duplas:

De um lado, o afastamento do corpo do circuito comunicativo, implicado no advento e na difusão da palavra impressa, parece ter encontrado, no recurso à auditividade, a promessa da proximidade negada pelas comunicações sociais típicas da modernidade. De outro lado, o recurso à autoridade transformava todo debate numa questão pessoal, em que discussão dos pressupostos era abandonada em favor de um silêncio reverente ou de uma loquacidade em eco. (ROCHA, 1998, p. 193).

A ligação ente a narração e a autoridade no âmbito de uma cultura auditiva se cristaliza na figura do "narrador-patriarca", cuja emergência na ficção oitocentista brasileira parece contradizer o processo da exclusão do corpo, iniciado com o advento da comunicação tipográfica que inviabiliza o contato imediato e interativo do emissor com os seus ouvintes:

No horizonte cordial, [...], parece ter surgido um narradorpatriarca, que substituía a multiplicidade de possíveis interpretações por constantes intervenções objetivadoras do relato. Deste modo, o narrador-patriarca procurou presentificar a ausência dos agentes mencionados na narrativa, assumindo o improvável papel de um corpo que despontaria em constantes explicações do enredo. [...] mais do que um princípio abstrato de ordenação narrativa, situado num espaço imaginário fora do texto, o narrador-patriarca é um narrador-corpo cuja presença deve ser visível no espaço mesmo do texto. (ROCHA, 1998, p. 203, grifo no original). 
Das observações de Rocha poderia surgir uma linha evolutiva muito simples: se a presença do narrador-patriarca, ou "um narrador que tutela seu leitor de modo paternalista" (LAJOLO; ZILBERMAN, [1996] 1998, p. 19), se opõe ao processo do gradativo apagamento textual do corpo e da alienação do leitor, privado da presença tutelar do seu contador de histórias, a formação da identidade moderna na literatura brasileira deveria equivaler a uma história da exclusão do narrador interveniente. Como mostram os exemplos dos narradores machadianos da segunda fase, bem como as figuras de Paulo Honório (narrador de S. Bernardo, de Graciliano Ramos) ou de Riobaldo (de Grande sertão: veredas, de João Guimarães Rosa), que procuram orientar o leitor nos seus próprios relatos, a proposta de Rocha indica antes a existência de outra modernidade literária, uma modernidade marcada pela fusão da esfera pública e privada, pelo recurso à oralidade como circunstância imediata, pelo recurso à autoridade, e, em consequência de todos esses fatores, pela auditividade. É uma modernidade que parece nutrir-se do oral, do particular e do local, em oposição ao projeto da modernidade europeia, baseado no princípio do distanciamento em busca de verdades universais ( $c f$. TOULMIN, [1990] 2005).

\section{LIBRANDI-ROCHA: ESCRITAS DE OUVIDO}

Na nota do rodapé no início do seu ensaio seminal, Luiz Costa Lima ([1978] 1981, p. 3) menciona o projeto de desenvolver um trabalho sobre o sistema intelectual no Brasil. Um dos aspectos que segundo o estudioso merecem uma retomada crítica - em nenhum lugar, porém, ele indica a segunda frente de pesquisa! - consta na necessidade de uma reflexão teórica sobre as características da auditividade em relação às culturas escrita e oral. Já no início deste século, em um texto em que insinua a existência de uma dimensão positiva da auditividade nas crônicas machadianas, Costa Lima (2002, p. 334, nota) revela que "tal estudo não foi levado adiante" e que até a publicação do livro de Rocha (1998) "os comentários nacionais [brasileiros] a propósito de auditividade se restringiram a tomá-la como sinônimo de oralidade ou simplesmente a ignoraram" (LIMA, 2002, p. 334, nota). A observação de Costa Lima é corroborada, por exemplo, pela referência à auditividade feita por Francisco Oititica Filho (2004), que simplificando a acepção do auditivo apresentada por Rocha - reduz o conceito à prevalência do oral sobre o escrito, da proximidade à distância, da familiaridade privada sobre a informalidade pública.

Os últimos anos, porém, proporcionam uma oportunidade para a releitura do conceito. No dia 4 de maio de 2015, a Faculdade de Letras da Universidade de São Paulo realizou a Jornada de Estudos "Oralidade e 
cultura escrita", cuja terceira parte foi dedicada à "Tensão entre escrita e oralidade na literatura brasileira do século XIX", e contou com contribuições de Hélio de Seixas Guimarães e Andrea Daher. Aliás, Guimarães começou, no início do ano de 2015, um projeto de pesquisa sobre "Escrita, oralidade e auditividade nas obras de José de Alencar e Machado de Assis", relacionando os resultados dos seus estudos anteriores na área da literatura oitocentista ( $c f$. GUIMARÃES, [2004] 2012) com as propostas de Costa Lima. ${ }^{7}$

A categoria da auditividade é retomada recentemente por Marília Librandi-Rocha ${ }^{8}$ Em 2011, a pesquisadora publica em inglês um artigo intitulado Writing by Ear: Clarice Lispector, Machado de Assis, and Guimarães Rosa and the Mimesis of Improvisation (LIBRANDI-ROCHA, 2011), que em uma versão ampliada sai na revista Literatura e Sociedade (9/2014), na segunda parte do dossiê temático “A voz". Nesse texto, a pesquisadora propõe um tipo de abordagem que consiste na operacionalização do conceito de auditividade para o estudo de um vasto leque de obras ficcionais brasileiras. Aceita-se, portanto, a afirmação inicial da existência de

uma qualidade distintiva da literatura brasileira: seu ouvido aguçado, ou em outras palavras, a proximidade de sua escrita com a captação de timbres e de nuances, acentuados no interior de uma cultura em que a oralidade e a musicalidade predominam. (LIBRANDI-ROCHA, 2014a, p. 132).

A pesquisadora estuda as autonarrativas ficcionais de Machado de Assis (em Memórias póstumas de Brás Cubas), Graciliano Ramos (em $S$. Bernardo) e Guimarães Rosa (em Grande sertão: veredas), ou seja, "três grandes nomes da literatura no Brasil", o que "pode confirmar a hipótese de que esse procedimento ["a duplicação autoral"] casa-se bem com uma tendência da expressão no Brasil marcada pela forte presença da oralidade e, por conseguinte, da auditividade" (LIBRANDI-ROCHA, 2014a, p. 145).

A pesquisadora concentra-se, sobretudo, na análise da dimensão sonora do texto e da experiência corporal reconstruível a partir dos escritos:

Minha sugestão é pensar o texto ficcional como se fosse uma caixa de música que pulsa e reverbera o vivido e o pensado em uma forma escrita, que ressoa novamente a cada leitura ao mesmo tempo em que se propaga no futuro cada vez que é reaberta. (LIBRANDI-ROCHA, 2014a, p. 133).

\footnotetext{
${ }^{7}$ Agradeço a Hélio de Seixas Guimarães a notícia da jornada realizada na USP.

${ }^{8}$ Agradeço a Luiz Costa Lima a indicação do trabalho de Librandi-Rocha.
} 
Esse tipo de abordagem parece, no entanto, perder a especificidade local do conceito, dado que a atualização sonora do texto escrito constitui (pelo menos para Kellogg e Ong) uma característica intrínseca do processo de leitura independentemente da cultura em que se realiza. Com isso, o foco de Librandi-Rocha orienta-se para a existência de um resíduo oral na literatura brasileira, e não para a auditividade enquanto um modo de comunicação marcado pela finalidade persuasiva. Descartando o aspecto da violência que impregna o conceito (relacionada, sobretudo, com o fim persuasivo fundamentado na obliteração das cadeias demonstrativas), a pesquisadora parece se afastar do núcleo do conceito de Costa Lima (pelo menos na sua versão inicial) que relaciona a estética com a política em condições socioculturais específicas. Em consequência, a auditividade se constitui, para Librandi-Rocha, uma atitude dos autores enquanto ouvintes atentos dos aspectos orais da sua própria cultura, capazes de se afastar até o ponto de se colocarem como estrangeiros e de transmitirem esse substrato oral na escrita. Nesse sentido, ela efetivamente pode ser apreendida enquanto uma consequência da oralidade da cultura brasileira. Dando esse passo, ela se distancia da sua dimensão persuasiva, mas se abre a novas e interessantes possibilidades interpretativas, como o conceito de "romance em eco" (cf. LIBRANDI-ROCHA, 2014b).

\section{ORAL VS. AUDITIVO: O PROBLEMA DA (DES) INTEGRAÇÃO}

Para finalizar, considera-se importante distinguir com ainda mais ênfase o conceito de auditividade da dimensão oral. Para este fim, propõe-se o artigo de Marisa Lajolo The Role of Orality in the Seduction of the Brazilian Reader: A National Challenge for Brazilian Writers of Fiction (1994), publicado na prestigiosa revista Poetics Today.

Sublinhando a persistência da tradição oral no Brasil oitocentista, em que não se podia observar quaisquer condições comparáveis às consequências da revolução industrial na Inglaterra, Lajolo (1994, p. 556) defende que:

Brazilian literature was expected from its inception to perform the same role that national literatures had played in Europe a century earlier: the shaping of a national bourgeois identity with corresponding feelings and emotional responses.

Nesse sentido, a educação do leitor - do qual dependeria a existência da literatura como instituição social moderna - equivaleria à sua 
sedução, introduzindo ao mesmo tempo novas práticas de leitura (LAJOLO, 1994, p. 556). Através de uma análise de textos literários, Lajolo procura mostrar que "orality might be one of the means (besides - or disguised as metafiction) by which the Brazilian reader was seduced in the mid-nineteenth century" (LAJOLO, 1994, p. 557). Trata-se aqui, sobretudo, das marcas da "oralidade residual" (residual orality), ou seja, dos elementos que evocam formas mais arcaicas de comunicação simbólica, persistentes no romance, a mais moderna das formas narrativas (LAJOLO, 1994, p. 557), apesar do seu caráter escritural.

No seu artigo, Lajolo analisa trechos de três obras oitocentistas. No caso de Lucíola (1862) de José de Alencar, sublinha o emprego da figura do manuscrito no final do relato como referência às práticas de escrita anteriores ao advento da cultura tipográfica (e do romance como seu gênero preferencial). Iracema (1865), do mesmo autor, alude à tradição dos relatos orais. A obra Inocência (1873), de Visconde de Taunay, com vários dialetos, numerosas epígrafes, notas de rodapé, aspas e itálicos que sinalizam uma pluralidade de vozes evocadas, aponta, conforme a pesquisadora, para a inadequação da forma romanesca às condições brasileiras específicas, falhando em representar a identidade heterogênea, dilacerada, da população do Brasil.

À consciência da diversidade cultural brasileira, visível em Taunay, que resulta numa constante reconstrução de uma identidade igualmente dilacerada, soma-se o problema principal discutido por Lajolo. Ao evocar as práticas antigas de comunicação oral, a ficção oitocentista brasileira inspirava "a reassuring sense of belonging, of ancestry and history, which evaded the risk of the loss of identity that readers and writers have to face in modern times" (LAJOLO, 1994, p. 558). Assim sendo, é possível estudar a presença da oralidade no romance oitocentista brasileiro como um processo de gradativa formação do leitor, que através da evocação das práticas orais podia "enjoy a feeling of intimacy and a warm relationship with narrators and thus to delay their exposure to the gap that has divided writers from readers in the modern era of the commodity novel" (LAJOLO, 1994, p. 563). Caso se aceite a hipótese de Lajolo, esse processo coincidia com a formação da identidade receptora moderna, ou seja, com uma identidade que se mostra cada vez mais familiarizada com os códigos de escrita originados pela modernidade.

Apreendendo a sedução referida pela estudiosa como um possível ponto de convergência da sua proposta com o estudo de Costa Lima, as marcas da oralidade analisadas por Lajolo equivaleriam aos mecanismos auditivos. Esse cotejo poderia sugerir uma contradição, dado que a valorização da oralidade/auditividade nos dois casos é muito divergente: enquanto Costa Lima sublinha a dimensão autoritária da auditividade que se

Miscelânea, Assis, v. 21, p. 31-50, jan.- jun. 2017. ISSN 1984-2899 
fundamenta na ausência de práticas demonstrativas, Lajolo alega que o recurso à oralidade tinha um aspecto de missão civilizadora, reduzindo a angústia dos leitores por meio de comentários metaficcionais que se concentram na organização do relato.

A incoerência mostra-se, no entanto, só aparente, desde que se admita a possibilidade da existência de dois planos em que a oralidade e a auditividade são presentes numa obra literária. No primeiro, em que se procura seduzir o leitor, evocam-se as práticas orais que permitem diminuir o efeito de estranhamento causado pelo romance como um gênero essencialmente escritural originado pela modernidade. Este nível, coincidente com a dimensão oral discutida por Lajolo, constitui o espaço de uma persuasão sedutora que procura a integração dos participantes do ato comunicativo. Nesse caso, o autor ensina ao leitor novas formas de recepção. O outro patamar, porém, é o domínio auditivo de uma persuasão sedutora que visa à submissão, isto é, à desagregação dos sujeitos. O emissor não procura a integração, mas antes reforça a sua superioridade em relação ao auditório. Dado que o discurso persuasivo na cultura auditiva não evidencia a sua própria construção, apresentando apenas o efeito final, a análise deste nível impõe dificuldades muito maiores.

\section{CONSIDERAÇÕES FINAIS}

Como se vê, o conceito de auditividade é uma noção dinâmica que ao longo da segunda metade do século XX sofreu alterações pertinentes e ainda continua a ser suscetível de evolução. Baseado na realidade sociocultural do Brasil, ele pode servir como ponto de partida ou ferramenta para estudos das interfaces entre a oralidade e a escrituralidade enquanto dimensões de uma literária, mas também das particularidades da construção de uma obra literária com um resíduo oral explícito, orientado, porém, para fins diversos.

\section{REFERÊNCIAS BIBLIOGRÁFICAS}

BENJAMIN, Walter. O narrador: considerações sobre a obra de Nikolai Leskov [1936]. In: . Magia e técnica, arte e política: ensaios sobre literatura e história da cultura. Tradução de S. P. Rouanet, 7. ed. São Paulo: Brasiliense, 1994, p. 197-221. 
BOROWSKI, Gabriel. A vantagem dos míopes: entre história e literatura. In: Studia Iberystyczne, Cracóvia, n. 13, 2014, p. 43-53.

CANDIDO, Antonio. Literatura e sociedade: estudos de teoria e história literária. 12. ed. Rio de Janeiro: Ouro sobre Azul, [1955] 2011.

. Formação da literatura brasileira: momentos decisivos. 15. ed. Rio de Janeiro: Ouro sobre Azul, [1959] 2014.

CHAUI, Marilena. Brasil: mito fundador e sociedade autoritária. São Paulo: Fundação Perseu Abramo, [2000] 2001.

CZAPLIŃSKI, Przemysław. Słowo i głos; Kalendarium badań nad twórczością ustną. In: (Org.). Literatura ustna. Gdańsk: słowo/obraz terytoria, 2010, p. 5-32, 354-371.

GALVÃO, Ana Maria de Oliveira de \& BATISTA, Antônio Augusto Gomes. Oralidade e escrita: uma revisão. In: Cadernos de Pesquisa, São Paulo, v. 36, n. 128 , mai./ago. 2006, p. 403-432.

GUIMARÃES, Hélio de Seixas. Os leitores de Machado de Assis: o romance machadiano e o público de literatura no século 19. 2. ed. São Paulo: Nankin/Edusp, [2004] 2012.

HAVELOCK, Eric. Oral composition in the Oedipus Tyrannus of Sophocles. In: New Literary History, Baltimore, v. 16, n. 1, 1984, p. 175-197.

HOLANDA, Sérgio Buarque de. Raízes do Brasil. 26. ed. São Paulo: Companhia das Letras, [1936] 1996.

KELLOGG, Robert. Oral literature. In: New Literary History, Baltimore, v. 5, n. 1, 1973, p. 55-66.

LAJOLO, Marisa. The role of orality in the seduction of the Brazilian reader: a national challenge for Brazilian writers of fiction. Poetics Today, Durham, v. 15 , n. 4,1994 , p. 553-567.

\& ZILBERMAN, Regina. A formação da leitura no Brasil. 2. ed. São Paulo: Ática, [1996] 1998.

LIBRANDI-ROCHA, Marília. "Writing by ear": Clarice Lispector, Machado de Assis, and Guimarães Rosa and the mimesis of improvisation. Critical Miscelânea, Assis, v. 21, p. 31-50, jan.- jun. 2017. ISSN 1984-2899 
Studies in Improvisation / Études critiques en improvisation, v. 7, n. 1, 2011, p. 1-11. Disponível em: <http://www.criticalimprov.com/article/view/1250>. Acesso em: 29 dez 2016.

. Escritas de ouvido na literatura brasileira. Literatura e Sociedade, São Paulo, n. 19, 2014a, p. 131-148.

Certo sentido íntimo: a audição na literatura brasileira. Brasiliana, Roma, ano 34, n. 150, 2014b, p. 19-33.

LIMA, Luiz Costa. Dispersa demanda: ensaios sobre literatura e teoria. Rio de Janeiro: Francisco Alves, 1981.

. Dependência cultural e estudos literários. In: . Pensando nos trópicos: dispersa demanda II. Rio de Janeiro: Rocco, 1991, p. 266-278.

. Machado: mestre de capoeira. In: Intervenções. São Paulo: Edusp, 2002, p. 327-339.

OLSON, David Richard. The world on paper: the conceptual and cognitive implications of writing and reading. Cambridge: Cambridge University Press, [1994] 1996.

ONG, Walter Jackson. From mimesis to irony: the distancing of voice. The Bulletin of the Midwest Modern Language Association, Chicago, v. 9, n. 1-2, 1976, p. 1-24.

. Romantyczna odmienność a poetyka technologii [1971]. In:

Osoba, świadomość, komunikacja: antologia. Tradução de: Japola, J. Warszawa: Wydawnictwa Uniwersytetu Warszawskiego, 2009. p. 27-53.

. Oralność i piśmienność: słowo poddane technologii. Tradução de: Japola, J. 2. wyd. popr. Warszawa: Wydawnictwa Uniwersyetu Warszawskiego, [1982] 2011.

ROCHA, João Cezar de Castro. Literatura e cordialidade: o público e o privado na literatura brasileira. Rio de Janeiro: Editora UERJ, 1998.

TOULMIN, Stephen. Kosmopolis: ukryty projekt nowoczesności. Tradução de: Zarębski, M. Wrocław: Wydawnictwo Naukowe Dolnośląskiej Szkoły Wyższej Edukacji TWP, [1990] 2005. 
Data de recebimento: 30 de dez. de 2016

Data de aprovação: 30 de abr.de 2017. 